it is known as Ubuntu, meaning 'togetherness' or, as the locals put it, 'I am because you are'. A sentiment we seem to have forgotten.
Leff J., Sartorius N., Jablensky A., et al (1992) The International Pilot Study of Schizophrenia: five-year follow-up findings. Psychological Medicine, 22, 131-145.

\title{
References
}

Leff J. (1988) Psychiatry Across the Globe - A Transcultural View. The

Royal College of Psychiatrists.

\section{SPECIAL PAPER \\ Mogadishu calling: mental health awareness in Somalia via an innovative, live video-based mental health teaching programme established between Liverpool and Mogadishu}

\author{
Yasir Abbasi, ${ }^{1}$ James Forryan,, ${ }^{2}$ Abdi Ahmed, ${ }^{3}$ Paul Kypriano ${ }^{4}$ and \\ Rebecca Martinez ${ }^{5}$
}

\begin{abstract}
${ }^{1}$ Clinical Director for Addiction Services, Mersey Care National Health Service Foundation Trust, Liverpool; Email: dryiabbasi@ yahoo.com

${ }^{2}$ Foundation Year, Aintree University Hospital, Liverpool ${ }^{3}$ Project Manager, Mersey Care National Health Service Foundation Trust, Liverpool

${ }^{4}$ Senior Researcher, Praxis Evaluation and Research,

Liverpool

${ }^{5}$ Consultant Psychiatrist, Mersey Care National Health Service

Foundation Trust, Liverpool

Conflicts of interest. None.

doi:10.1192/bji.2017.30

(c) The Authors 2018. This is an Open Access article, distributed under the terms of the Creative Commons AttributionNonCommercial-NoDerivatives licence (http://creativecommons. org/icenses/by-nc-nd/4.0/), which org/licenses/by-nc-nd/4.0/), whic permits non-commercial re-use, distribution, and reproduction
any medium, provided the original work is unaltered and is properly cited. The written permission of Cambridge University Press must be obtained for comPress must be obtained for com-
mercial re-use or in order to create a derivative work.
\end{abstract}

In 2013 the Federal Government of Somalia contacted the Mersey Care National Health Service Foundation Trust (MCFT), asking whether they could formulate a teaching programme tailored towards improving mental health provision in Somalia, and the E-learning Mental Health Training Programme (SOM-Health) was eventually conceived. The fundamental aim was to provide mental health awareness to practitioners and trainees in Somalia so that they could deliver mental healthcare services confidently and effectively.

\section{Background}

Somalia has a population of 11265116 (in 2017), with a total life expectancy of 55 years (WHO, 2015; Worldometers.info, 2017). There are few mental health services in Somalia, which is incongruous to the country's need. Since the outbreak of civil war in 1991, the country has been plagued by conflict and unrest. A huge number of Somali citizens have been subjected to torture, beatings, rape and have suffered life-changing injuries; others will have witnessed such atrocities being committed to loved ones and friends. Many mental health diagnoses can be traced back to substance misuse involving khat, the leaves traditionally consumed in Somalia that are laden with the amphetamine-like chemical cathinone (WHO, 2010). Unsurprisingly, the World Health Organization (WHO) reports that one in three Somalis have been affected by some form of mental illness (this figure exceeds that seen in other comparable low-income countries) (WHO, 2011). Furthermore, a culturally derived lack of understanding of mental illness compounds the issue. Through misconceptions and sometimes antiquated cultural beliefs, people with mental illness are often ostracised, stigmatised and even imprisoned or chained against their will (Hooper, 2013). In fact, between 2000 and 2010, 90\% of mental health patients had been subjected to at least one episode of chaining, a practice both ubiquitous and indeed endorsed in many mental health facilities within Somalia (WHO, 2010).

\section{Scoping report}

The initial scoping report, conducted in October 2013 (and updated in June 2015), was carried out by Praxis.

\section{Safety}

Outcomes underlined that an 'on the ground' programme would not be feasible in light of the endemic political and security situations precluding the travel of staff to Somalia. Nevertheless, the scoping report felt that teaching and assistance via distance learning remained extremely viable, especially with the improvements in technology and internet access in Somalia.

\section{Models}

Praxis identified the work of the King's Tropical Health and Education Partnership (KTSP) as a potential blueprint that Mersey Care National Health Service Foundation Trust (MCFT) could reproduce. KTSP has developed basic psychiatry courses for final year medical students at two partner universities and peer-to-peer learning sessions for both medical students and nursing students (THET, 2002; WHO, 2013). 


\section{The programme}

The programme itself was devised with the help of a three-pronged collaboration between volunteers from MCFT, the Habeb Mental Health Foundation (HMHF) and the UK charity Human Development for Concern for Horn of Africa (HDCHA). The course content was accredited by a core of volunteer tutors. The programme consisted of 12 3-hour sessions delivered fortnightly, with the closing 30 minutes allowing for questions and discussion. The volunteer tutors varied from healthcare assistants to consultant psychiatrists. We developed a short 'meet-your-tutors' video which played at the first session (https://youtu.be/2MwRHFKM4g4).

\section{Delivery}

The first session was delivered on 1 October 2015 with sequential sessions provided every 2-3 weeks until its culmination on 17 March 2016. There were initially 48 participants, many of which were from HMHF but also from WARDI Relief and Development Initiatives, Horseed International University, Shifo Hospital, Salaam University, Dr Hawa Abdi Foundation and Shifa Health Science University. The cohort included both Mogadishu residents and those travelling from afar (the furthest being several hundred miles). Three of the male participants were forced to drop out due to their long travel distances and the resulting cost. Similarly, several female participants left the course early because of safety issues, with the late finish times coinciding with nighttime journeys home.

\section{Breakdown of course participants}

Following the initial loss in participant numbers, 35 individuals remained enrolled in the programme. Four people of this cohort had completed WHO mental health training in 2004, revalidating this in 2009. A number of others had received training through HMHF. Of the 35 participants, there were 19 nurses, 5 nursing assistants, 7 doctors and the remaining participants had other roles.

A baseline survey was conducted at the outset of the programme and results showed that almost half $(n=16)$ of the participants rated their knowledge of the treatment of mental health problems as poor, 11 participants rated it as $\mathrm{OK}$ and merely 8 were confident enough to mark it as good (note that three participants provided no response).

Participants were then asked about the extent to which they felt they were armed with the requisite skills in treating and attending to those with mental health problems. Just 1 of the 35 felt 'fully' equipped, with another participant saying 'mostly'. The majority $(n=17)$ believed they were 'partially' equipped, 13 reporting 'to a small extent' and 3 'not at all'.

Considering the previous data, it is unsurprising that when participants were asked to rate their confidence in adequately meeting the needs of patients with mental health problems, they broadly fell towards the lower end of the scale: 6 reported being 'not confident at all', 9 had 'not much confidence', 12 were 'partially confident', 6 were 'mostly confident and just 2 were 'fully confident'.

\section{Outcomes}

Overall, the project garnered extremely positive feedback from the participants and those providing the training. Several interviews were conducted to obtain subjective data on the programme. Interviewees from Somalia included the coordinator, the Director of HMHF and, as participants, one of the nurses and a social worker. Interviewees from Liverpool included the MCFT Clinical Director, Director for Commissioning and the Project Manager.

Dr Mustafa Abdirnaham Ali (coordinator in $\mathrm{HMHFH}$ ) praised the programme, specifically in relation to the gap it was able to fill within the healthcare system in Somalia, and the very evident value it brought to participants. However, he did feel that securing accreditation in the future would be advantageous in expanding the project. He is quoted as saying:

\begin{abstract}
'We really appreciate all the efforts Mersey Care staff gone through to put this programme together and make it flexible to support and optimise our learning. I want to commend Mersey Care for their wonderful work and knowledge given to us. I want to also say a big thanks for this opportunity given to us to learn and participate in this pioneering initiative.
\end{abstract}

The Director of HMHF was in agreement with the Dr Abdirnaham Ali's comments and he went on to further stress the importance of continuing to improve knowledge and skills of the staff within the Foundation as well as extending the programme to other health workers in the surrounding area.

An unqualified nurse who took part in the programme said:

'The courses have re-energized me and my approach to diagnosing patients. I am now much more confident and eager to put this knowledge into practice. I feel I now have the understanding to tackle the most difficult patients I'm responsible for.'

A social worker from Shifo Mental Hospital commented:

'I truly appreciated Mersey Care training staff professionalism, knowledge and patience with the class. I enjoyed the course and found the material very useful in my work. I also liked the presentation style.

Dr Yasir Abbasi, Clinical Director and Consultant Psychiatrist in Addiction Services at MCFT and the Project Director re-iterated these observations. He was also keen to draw attention to the positive experience the programme provided for the trainers. It demanded that they consider and explore the dilemma of managing mental health patients with minimal resources and funding, a scenario with which they are not faced in their own practices within the UK. He was quoted as saying: 
'As a trainer, it gave me great insight in to trans-cultural practices and their implication on mental health- This has improved my confidence in dealing with and discussing mental health issues with local Somali diaspora whilst being culturally sensitive at the same time.'

\section{Options moving forwards}

The principal, and most natural, next step would likely be in furthering the MCFT partnership with $\mathrm{HMHF}$, and facilitating continued distance learning. This would be directly linked to exploring the capacity for establishing a secure, neutral site within southern Somalia in which face-to-face training could be instigated. Furthermore, as suggested by the programme coordinator in Somalia, procuring accreditation would potentially incentivise reluctant participants and act to further raise the public profile of mental health in the country. Finally, such programmes can help give insight into the cultural understanding of mental health problems and possibly help us to evaluate the extent of the psychiatric morbidity within the Liverpool-based Somali diaspora. Research into this area could possibly identify any unmet healthcare needs. If this was the case, plans could then be drawn up to meet these needs.

\section{References}

Hooper R. (2013) Where hyenas are used to treat mental illness. BBC News [online], 17 October. Available at http://www.bbc.co.uk/news/ magazine-24539989 (accessed 4 February 2017).

Tropical Health and Education Trust (THET) (2002) Kings-THET Somaliland Partnership (KTSP). THET. Available at https://www.rcpe.ac. uk/international/kings-thet-somaliland-partnership (accessed 4 February 2017).

World Health Organization (WHO) (2010) A Situation Analysis of Mental Health in Somalia. World Health Organization. Available at http://applications.emro.who.int/dsaf/EMROPUB_2010_EN_736.pdf (accessed 4 February 2017).

World Health Organization (WHO) (2011) Mental Health in Somalia. World Health Organization [online]. Available at http://www.who.int/ hac/crises/som/somalia_mental_health/en/ (accessed 28 January 2017).

World Health Organization (WHO) (2013) Building Back Better: Sustainable Mental Health Care After Emergencies. World Health Organization. Available at http://www.who.int/ mental_health/emergencies/building_back_better/en/ (accessed 4 February 2017).

World Health Organization (WHO) (2015) Somalia. World Health Organization [online]. Available at http://www.who.int/countries/som/ en/ (accessed 4 February 2017).

Worldometers.info (2017) Somalia Population (2017). Worldometers. info [online]. Available at http://www.worldometers.info/ world-population/somalia-population/ (accessed 4 February 2017).

\title{
SPECIAL PAPER \\ A qualitative study assessing the feasibility of implementing a group cognitive-behavioural therapy-based intervention in Sierra Leone
}

\author{
Samantha Waterman, ${ }^{1}$ Charles L. Cole, ${ }^{2}$ Neil Greenberg, ${ }^{3}$ G. James Rubin ${ }^{4}$ \\ and Alison Beck ${ }^{5}$
}

\section{Assistant Psychologist, South London and Maudsley NHS Foundation Trust, UK; email samantha.waterman@nhs.net ${ }^{2}$ Assistant Psychologist, Division of Psychiatry, University College London, UK \\ ${ }^{3}$ Professor of Defence Mental Health, Institute of Psychiatry, Psychology and Neuroscience, Psychology and Neuroscien
King's College London, UK ${ }^{4}$ Reader in the Psychology of Emerging Health Risks, Institute of Psychiatry, Psychology and Neuroscience, King's College London, UK \\ ${ }^{5}$ Head of Psychology and Psychotherapy, South London and Maudsley NHS Foundation Trust, UK}

Acknowledgements. We thank Idit Albert, Annis Cohen, Sarah Coleman, Jennifer Foster, Jennife House, Elaine Hunter, Mary Ion, Alison Jones, Ukwuori-Gisela Kalu, Kathy Nairne, Clare Reeder, Andy Sweeting, Klya Vailancourt and
Mental health support in Sierra Leone is sparse, and qualitative research into the feasibility of implementing psychological interventions is equally underdeveloped. Following the 2014 Ebola virus disease outbreak, South London and Maudsley NHS Trust were commissioned to develop a psychological intervention that UK clinicians could train national staff with minimal psychological experience to deliver to their peers. Following the completion of the stepped care, group-based cognitivebehavioural therapy intervention, qualitative interviews were conducted with the national team to identify key barriers and enablers to implementation of and engagement with this intervention. This article describes the key themes that came out of those interviews, and discusses the implications of these findings for future clinical teams.
Mental health support in Sierra Leone is largely limited to support from families, local communities and traditional healers (Alemnu et al, 2012). There is no modern mental health legislation and no specific budget for mental health (WHO, 2010). In addition, there are high levels of stigma surrounding mental ill-health.

During the 2014-2015 Ebola virus disease (EVD) outbreak in West Africa, Ebola treatment centres (ETCs) were set up across Sierra Leone and staffed by a combination of national and international healthcare workers. These staff were exposed not only to significant risk of infection with the disease, which is highly contagious (Gulland, 2014), but also to traumatic scenes of human suffering on a daily basis (Paladino et al, 2017). There is a significant body of evidence that experiencing trauma increases a person's susceptibility to mental health difficulties (Thormar et al, 2013; West et al, 2008). 